\title{
Aislamiento de bacilos Gram negativos y Estafilococos, posterior a dos técnicas de lavado de manos, en estudiantes de Enfermería que realizan prácticas hospitalarias
}

\author{
Isolation of Gram-negative bacilli and Staphylococci, after two handwashing \\ techniques, in Nursing students who perform hospital practices
}

\author{
Raquel Orellana Guevara ${ }^{1}$, Celia Colque Flores², Max Abel Yugar Mier ${ }^{3}$
}

\begin{abstract}
RESUMEN
Objetivo: El propósito de la investigación fue el aislamiento de microorganismos del género Staphylococcus y Bacilos Gram negativos posterior a dos técnicas de lavado de manos, durante las prácticas de laboratorio de los estudiantes de Enfermería. Metodología: La investigación fue de tipo correlacional y transversal, realizada en mayo de 2018; los participantes fueron 40 estudiantes distribuidos en dos grupos (Grupos control y experimental). Las muestras se tomaron por hisopado de las manos recientemente lavadas. Se aplicó el lavado de manos clínico (LMC) de 11 pasos en el grupo control y el LMC de 3 tiempos en el grupo experimental, previa capacitación. El aislamiento, identificación y recuento microbiano se efectuó en medios de cultivos adecuados y selectivos. Los datos se procesaron en el programa Excel, mediante pruebas de significación estadística y estadísticos descriptivos. Resultados: Se aisló Staphylococcus cuagulasa negativo en un $40 \%$ del total de participantes; según el tipo de lavado se encontró este microorganismo en un $50 \%$ de participantes que aplicaron el LMC de 11 pasos, y en un $30 \%$ de participantes tras el LMC de 3 tiempos. Respecto a la búsqueda de bacilos Gram negativos, se encontró Klebsiella spp en un $5 \%$ del total de participantes en el LMC de 3 tiempos. Los recuentos bacterianos fueron más bajos en el LMC de 3 tiempos y se obtuvo diferencia estadísticamente significativa de $p=0.033(p \leq 0.05)$ al comparar ambas técnicas de lavado. Conclusiones: Hubo diferencia entre las dos técnicas de lavado de manos en los recuentos bacterianos, hallándose mayor crecimiento tras el LMC de 11 pasos, y menor crecimiento en el LMC de 3 tiempos. El microorganismo más frecuente fue Staphylococcus cuagulasa negativo y en un mínimo de muestras, Klebsiella spp.
\end{abstract}

Palabras clave: Lavado de manos, Staphylococcus, Bacilos Gram negativos

\section{ABSTRACT}

Objective: The purpose of the research was the isolation of microorganisms of the genus Staphylococcus and Bacillus Gram negative after two handwashing techniques, during the laboratory practices of nursing students. Methodology: The research was correlational and transversal, carried out in May 2018; The participants were 40 students distributed in two groups (Control and experimental groups). Samples were taken by swab from recently washed hands. The 11-step clinical handwashing (CML) was applied in the control group and the 3-cycle CML in the experimental group, after training. Isolation, identification and microbial count was carried out in suitable and selective culture media. The data was processed in the Excel program, using tests of statistical significance and descriptive statistics. Results: Negative Staphylococcus cuagulase was isolated in $40 \%$ of the total participants;

${ }^{1}$ Universidad Adventista de Bolivia, Cochabamba, Bolivia.

Orcid ID: 0000-0002-4835-5789

2Universidad Adventista de Bolivia, Cochabamba, Bolivia.

Orcid ID: 0000-0002-0975-3602

${ }^{3}$ Universidad Adventista de Bolivia, Cochabamba, Bolivia. 
Depending on the type of washing this microorganism was found in $50 \%$ of participants who applied the 11-step CML, and in 30\% of participants after the 3-stroke CML. Regarding the search for Gramnegative bacilli, Klebsiella spp was found in $5 \%$ of the total participants in the 3 -stroke CML. Bacterial counts were lower in the 3-stroke CML and a statistically significant difference of $p=0.033(p \leq 0.05)$ was obtained when comparing both washing techniques. Conclusions: There was a difference between the two handwashing techniques in bacterial counts, with greater growth after the 11-step CML, and lower growth in the 3-stroke CML. The most frequent microorganism was Staphylococcus cuagulase negative and in a minimum of samples, Klebsiella spp.

Keywords: Handwashing, Staphylococcus, Gram negative bacilli

\section{INTRODUCCIÓN}

La transmisión de microorganismos que causan enfermedad se da por diversos mecanismos que facilitan la supervivencia y crecimiento de los mismos en distintos nichos ecológicos, así como su transmisión de un huésped a otro.

Según la OMS (2014), las manos son el principal vehículo de contaminación exógena de infecciones nosocomiales y el lavado de manos tiene la finalidad de minimizar la transmisión de infecciones entre los pacientes y el personal. Por tanto, el lavado de manos se considera la práctica de antisepsia, prevención control de infecciones, sencilla e importante, que debe realizar el personal de salud en todas las unidades de atención. La exigencia de esta práctica es también para los estudiantes de enfermería.

Según Allegranzi, Kilpatrick y Pittet (2011), el lavado de manos con agua y jabón es el procedimiento más efectivo y económico para prevenir las infecciones nosocomiales, el simple hecho de aplicar esta técnica evita la propagación de gérmenes patógenos en los pacientes. Se estima que en cada centímetro cúbico pueden sobrevivir 3000 tipos de microorganismos hasta más de veinte minutos en la superficie de los objetos del entorno.

Córdova et al (2011) y García et al, 2016 declararon que en la piel de las manos se encuentra microbiota habitual, lo cual se demuestra en cultivos, aislándose distintos tipos de gérmenes que si bien no son de gran importancia en personas inmunocompetentes, su transmisión a pacientes inmunodeprimidos representa un riesgo de enfermedad muy elevado. Por otra parte, existen individuos portadores de gérmenes patógenos en sus manos, lo cual implica riesgo elevado de transmisión. Dentro de éstos se encuentran microrganismos del género Staphylococcus y distintos géneros de bacilos Gram negativos.

Según Marples y Torres (2012) estudiaron sobre la transmisión de los agentes infecciosos usando diferentes modelos experimentales, solicitaron a enfermeras que tocaran la piel del paciente durante 15 segunda, luego se les pidió que se lavaran las manos con agua y jabón haciendo una fricción vigorosa. Después del lavado de manos, tocaron un trazo de catéter urinario con sus dedos y el segmento del catéter se cultivó. El estudio revelo que tocar áreas de piel intacta transfiere microorganismos a las manos del personal de enfermería para permitir su posterior transmisión al catéter, a pesar de haberse lavado las manos con agua y jabón. Por lo tanto la importancia del lavado de manos debiera ser rigurosa durante la atención del paciente.

La OMS, acorde a la evidencia científica de la transmisión de gérmenes a través de manos, ha establecido que el lavado de manos clínico (de 11 pasos) debe realizarse en 5 momentos: 1) Antes del contacto con el paciente, este momento se origina antes de ponerse en contacto con la piel intacta y la ropa del paciente. Para protegerlo de los microrganismos patógenos que puedan estar en las manos. 2) Antes de realizar una tarea aséptica, este momento se produce inmediatamente antes de acceder a un sitio crítico con riesgo de infección para el paciente como procedimientos que implique un contacto directo e indirecto con mucosas, piel no intacta o un dispositivo invasivo. 3) Después del riesgo de exposición a fluidos orgánicos, este momento se produce cuando se ha terminado un cuidado al paciente que ocasiona riesgo de exposición a fluidos corporales y el próximo contacto con cualquier superficie, incluyendo el paciente, el entorno del paciente o el área 
de salud. 4) Después del contacto con el paciente, este momento se produce al alejarse del paciente, después de haber tenido contacto con él o superficie de en su entorno. 5) Después del contacto con el entorno del paciente, este momento se produce después de tener contacto con cualquier objeto o mobiliario al salir del entorno del paciente.

La OMS (2009) El cumplimiento de esta práctica reduce el índice de morbimortalidad causadas por infecciones nosocomiales, disminuyendo de esta manera la prolongación de los días de hospitalización de los pacientes. (11 pasos).

$\mathrm{Si}$ se toma en cuenta las infecciones intrahospitalarias, en su estudio Oliveira, Marques y Prado (2017) señalaron que los microorganismos más frecuentes son Staphylococcus con un $30 \%$, Candida $23.3 \%$, Klebsiella pneumoniae y Pseudomonas aeruginosa $13.3 \%$. Estos datos indican que el personal de salud y estudiantes, se encuentran expuestos a adquirir estos gérmenes y ser portadores.

Por otra parte, cultivos microbiológicos realizados a partir de piel y mucosas del personal y estudiantes del área de salud, demuestran la identificación de distintos tipos de gérmenes, con y sin la aplicación de asepsia y lavados de manos.

Según Córdova, et al (2011) se encontró una prevalencia de Staphylococcus aureus de $12.98 \%$ en muestras de hisopado de manos y fosas nasales y solo en manos, $10.7 \%$. Esta prevalencia fue baja y se evidenció que ante el uso de medidas de protección la frecuencia de portadores era menor.

Según García, et al. (2016), en una investigación sobre identificación de crecimiento bacteriano en las manos de estudiantes universitarios de ciencias de la salud, se encontró que el $50 \%$ de las muestras presentaban crecimiento, sin diferenciar carrera ni semestre, y se concluyó que el grupo carecía del hábito correcto de lavado de manos, situación necesaria de revertir para prestar un servicio de mejor calidad.

De acuerdo con Bustamente, Nuñez, Arellano y Navarro, (2018), en una investigación, "Bioluminiscencia: Herramienta de medición y análisis en lavado de manos clínico aplicado a Odontología", se encontró una diferencia significativa en mediciones de aceptación y rechazo de contaminación, antes y después del lavado de manos clínico, y una mayor prolijidad en el lavado que aplican las mujeres.

La presente investigación tuvo como finalidad el aislamiento de Staphylococcus y Bacilos Gram negativos, posterior a dos técnicas de lavado de manos, durante las prácticas de laboratorio de los estudiantes de Enfermería. Se utilizó un programa de capacitación previa en el grupo experimental. Se tomó este tipo de microorganismos debido a la importancia clínica que presentan.

\section{METODOLOGÍA}

Es estudio fue experimental, correlacional y transversal. Se efectuó en estudiantes de la Carrera de Enfermería de la Universidad Adventista de Bolivia, de todos los semestres. Entre los criterios de inclusión se tomó a estudiantes de Enfermería que realicen prácticas, desde primero hasta noveno semestre (primero, tercero, quinto, séptimo y noveno).

La población fue de 79 estudiantes. Se tomó una muestra de 40 estudiantes en dos grupos. Los dos grupos de estudios se seleccionaron de manera aleatoria tanto el grupo control con el lavado de manos con los 11 pasos, y el grupo experimental con lavado de manos en tres tiempos.

. Un grupo control de 20 estudiantes, quienes realizaron el lavado clínico de manos, que habitualmente se ejecuta antes de su práctica. Cabe destacar que no se alertó a este grupo sobre la toma de muestra para cultivo microbiológico; un segundo grupo de 20 estudiantes, recibió una capacitación previa sobre el lavado de manos en 3 tiempos, procediéndose a la aplicación de este tipo de lavado y la consiguiente toma de muestra para cultivo microbiológico. Los dos muestreos fueron el 28 de mayo y 6 de junio de 2018 respectivamente.

\section{Aplicación de lavado de manos clínico}

Se aplicó al primer grupo de estudiantes (grupo control). Se les indico que realizasen el lavado de manos con los 11 pasos según la OMS. Para el lavado de manos se les proporcionó los materiales como jabón líquido y papel toalla. $\mathrm{EI}$ 
tiempo de lavado de manos tuvo una duración de 2 minutos. El procedimiento fue el siguiente:

1. Se realizó mojado de manos con agua

2. Se Aplicó jabón para a las manos

3. Seguidamente hizo frotado de las palmas de las manos entre sí

4. Frotado de palma de la mano derecha contra el dorso de la mano izquierda, con los dedos entrelazados y viceversa.

5. Frotado de las palmas de las manos entre sí, con los dedos entrelazados.

6. Frotado del dorso de los dedos de una mano contra la palma de las manos opuesta, manteniendo unidos los dedos.

7. Rodeando el pulgar izquierdo con la palma de la mano derecha, frotado con movimiento de rotación y viceversa

8. Frotado de la punta de los dedos de la mano derecha contra la palma de la mano izquierda, haciendo un movimiento de rotación y viceversa

9. Enjugado de las manos

10. Secado con una toalla desechable

11. Cierre del grifo o llave de agua con la toalla desechable.

Capacitación en lavado de manos en tres tiempos

Se capacitó a los estudiantes, dividiéndolos en grupos de 5 personas. Se demostró para ellos el procedimiento del lavado de manos en tres tiempos:

\section{Primer tiempo}

1. Mojar las manos con agua, incluyendo la palma, dorso y muñeca

2. Aplicar suficiente jabón para cubrir toda la superficie de la mano

3. Frote circular de la palma de las manos 5 veces
4. Frote circular el dorso de la mano cinco veces

5. Frote de la muñeca en forma circular de ambas manos

6. Enjugar con abundante agua iniciando palma, dorso y muñeca de ambas manos

\section{Segundo tiempo}

7. Aplicar jabón en la palma de la mano

8. Frote de las palmas de las manos en forma enérgica 5 veces

9. Frote de interdígitos de ambas manos por cinco veces

10. Frote en forma circular dedo por dedo de ambas manos

11. Frotar la punta de los dedos de la mano derecha contra la palma de la mano izquierda, haciendo un movimiento de rotación y viceversa

12. Enjugar las manos con abundante agua, frotando de forma enérgica.

13. Secado de manos dedo por dedo, iniciando en el dorso, palma y terminado con muñeca

14. Cierre de la llave de grifo con el papel

\section{Tercer tiempo}

Primer bombeo del antiséptico

- Aplicación de antiséptico en la palma de la mano izquierda

- Con los dedos de la mano derecha frotar en forma circular

- Con el restante del antiséptico que quedo en la palma de la mano izquierda, frotar la muñeca de la mano derecha.

Segundo bombeo del antiséptico

- Aplicación de antiséptico en la palma de la mano derecha

- Con los dedos de la mano izquierda frotar en forma circular 
- Con el restante del antiséptico que quedo en la palma de la mano derecha frotar la muñeca de la mano izquierda.

\section{Tercer bombeo del antiséptico}

- Aplicación de antiséptico en la palma de la mano

- Frote de palmas, iterdígitos y dorso hasta que se pierda antiséptico

Después de la capacitación del procedimiento el grupo de estudio realizó el lavado de manos según lo indicado, para este procedimiento se les proporciono jabón líquido, alcohol en gel como antiséptico (ambos de marca LIZ) y papel toalla. Ambos productos fueron sin uso previo.

\section{Preparación de medios de cultivo}

Se preparó medios de cultivo sólidos: Agar nutritivo, agar Mac. Conkey, agar manitol salado y agares para pruebas bioquímicas (TSI, citrato, lisina, urea, SIM), disolviendo cada uno en la proporción indicada por el fabricante, se llevó a ebullición por un minuto y se esterilizó a $121^{\circ} \mathrm{C}$ por 15 minutos. Luego se procedió a vaciar para su solidificación, los medios agar nutritivo y agar Mac Conkey se colocó en cajas de Petri y los demás medios en tubos de ensayo. Todo el material utilizado fue estéril comprobándose a través del cambio de color de una cinta testigo.

Se preparó además caldo Muller Hinton, con la finalidad aumentar la probabilidad del aislamiento de gérmenes patógenos.

\section{Toma de muestra y cultivo}

Se dispensó solución fisiológica estéril en tubos de hemólisis en alícuotas de $1 \mathrm{ml}$. Luego del lavado de manos, de manera inmediata se procedió a realizar un hisopado, haciendo un barrido de toda la mano con el hisopo previamente humedecido. Se tomó la muestra de una mano, la más utilizada por el estudiante. Posteriormente se suspendió el hisopo en el tubo con solución fisiológica.

\section{Cultivo en Agar nutritivo}

Una vez obtenidas las muestras se procedió la siembra en agar nutritivo. Para ello se agitó el tubo con la muestra en un vortex y se tomó 100 ul., vaciándose sobre el agar nutritivo. Se extendió en toda la superficie utilizando un asa de Digralsky. Se cultivó durante 48 horas a $37^{\circ} \mathrm{C}$ en estufa bacteriológica, realizándose luego el recuento de colonias.

\section{Cultivo en medio líquido}

Después de la siembra en agar nutritivo, el hisopo de cada muestra fue introducido en $1 \mathrm{ml}$. De caldo Muller Hinton y se cultivó por 24 hrs. A $37^{\circ} \mathrm{C}$, se hizo luego una siembra a partir de este medio líquido en Agar Mac Conkey y Agar manitol salado con la finalidad de aislar bacilos Gram negativos y Staphylococcus aureus respectivamente.

\section{Siembra directa en Agar Mac Conkey}

La muestra obtenida en solución fisiológica fue sembrada, de forma masiva, en agar Mac Conkey en el mismo día de su obtención.

La verificación del crecimiento en agar manitol salado y agar Mac Conkey se realizó a las 24 y 48 hrs. Tras un crecimiento positivo se realizó tinción de Gram a partir de colonias representativas.

Para bacilos Gram negativos se realizó serie bioquímica para la identificación de especie a partir de colonias de agar Mac Conkey.

\section{Pruebas bioquímicas de catalasa y coagulasa}

Se realizó la prueba de catalasa, que consiste en colocar en contacto a los microorganismos, a partir de un cultivo, con una solución de peróxido de hidrógeno, considerando la producción de gas (burbujas) como reacción catalasa positiva, que identifica al género Staphylococcus.

Para la identificación de Staphylococcus aureus se realizó la prueba de coagulasa, que consiste en colocar en contacto a los Staphylocuccus con plasma sanguíneo, tomándose como catalasa positiva a la formación de coágulo.

\section{RESULTADOS}

La efectividad del lavado de manos se evaluó en 40 estudiantes de los que $5(12,5 \%)$ fueron del género masculino y 35 (87.5\%) del género femenino. 
El gráfico 1 muestra la distribución general de los estudiantes por semestre. Se puede observar que la mayoría de los participantes corresponden al primero y noveno semestre.

El cultivo se realizó en dos grupos. Un primer grupo $(n=20)$, que realizó el lavado de manos clínico de 11 pasos (LMC 11 pasos) que fue considerado como GRUPO CONTROL y un segundo grupo $(n=20)$, que aplicó el lavado de manos en 3 tiempos (LMC 3 tiempos), GRUPO EXPERIMENTAL. En el recuento total de microorganimos, realizado en agar nutritivo, se obtuvieron los siguientes resultados: En el grupo control, se obtuvo crecimiento en el $100 \%$ de las muestras y en el grupo de LMC 3 tiempos en el $95 \%$.

Gráfico № 1

Distribución de estudiantes por curso

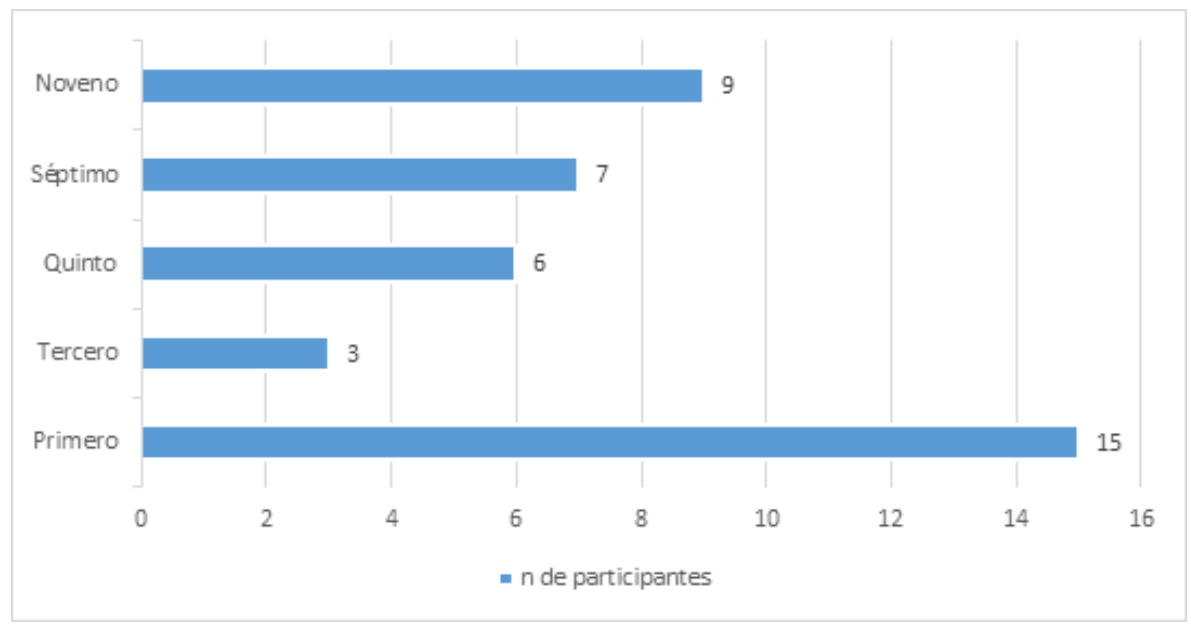

En gráfico 2 se puede observar que en el grupo control hubo mayor crecimiento en los recuentos mayores a 100 UFC, siendo este de 35\%, mientras que en LMC 3 tiempos solo un $15 \%$ presentó este tipo de recuento. Por otro lado, en el recuento menor o igual a 10 UFC se puede observar un $25 \%$ de muestras dentro del grupo control y un $40 \%$ de muestras en el grupo de LMC 3 tiempos. Esto indica que los recuentos bajos son más frecuentes en grupo experimental.

Gráfico №2

Crecimiento total de microorganismos en ambos grupos

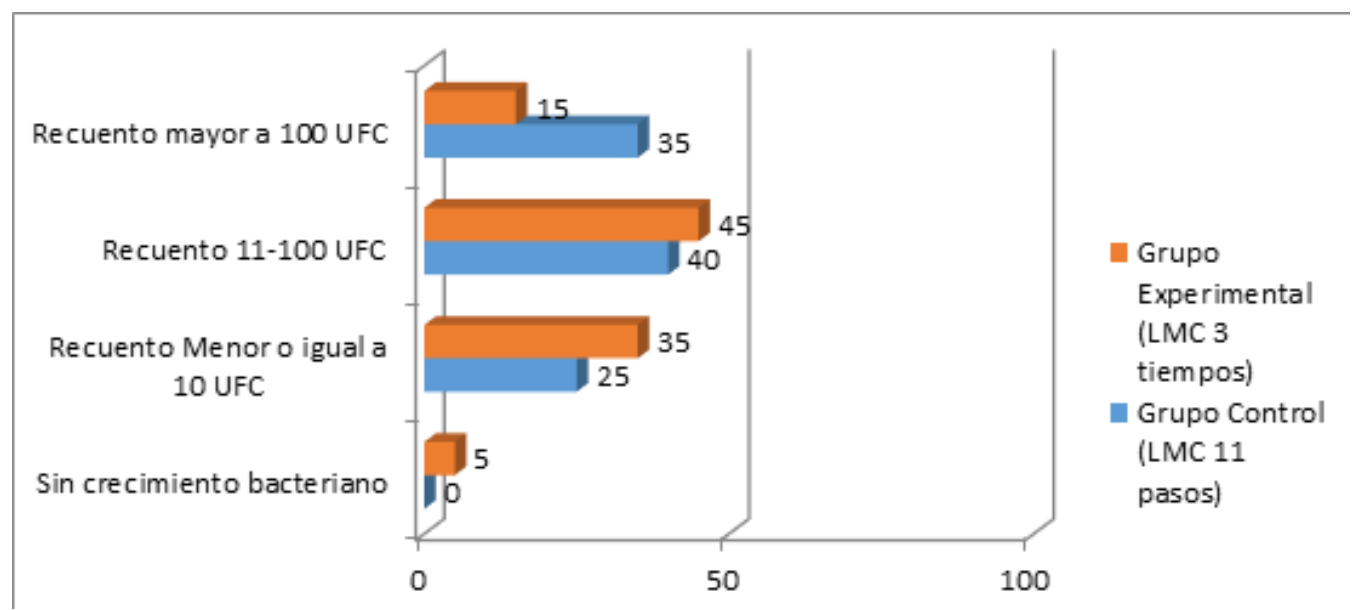


Los resultados del muestreo hecho a través de ambas técnicas de lavado de manos, en los recuentos totales exhibieron que el valor de media es significativamente distinto en ambos grupos. El grupo control tuvo una media de 162,25 UFC en los recuentos totales y el grupo de LMC 3 tiempos mostró una media de 32,32 UFC.

El análisis estadístico de comparación de medias a través de la prueba de $\mathrm{F}$ de Fisher para muestras independientes muestra un valor $p=0.033(p<0.05)$, de la misma manera el estadístico de Fisher indica que existe diferencia significativa entre los grupos de control y experimental de lavado de manos.

Respecto al crecimiento de microorganismos patógenos, el cultivo selectivo para el género Staphylococcus, realizado en agar manitol salado, se consideró el crecimiento positivo comprobándose a través de la tinción de Gram y prueba de la catalasa, para el género Staphylococcus y la prueba de coagulasa para la detección de Staphylocuccus aureus. Los resultados se muestran en la Gráfico 3, donde se evidencia que, en un $n=20$ para cada uno de los grupos, en el grupo control, 10 (50\%) presentaron Staphylococcus coagulasa negativo. En comparación, el grupo de LMC 3 tiempos, $6(30 \%)$ presentaron este microorganismo. No se aisló Staphylococcus aureus en ninguna de las muestras.

Si se toma en cuenta los 40 participantes e independientemente de la técnica de lavado, se identificó crecimiento de Staphylococcus coagulasa negativo en $16(40 \%)$ muestras de los participantes.

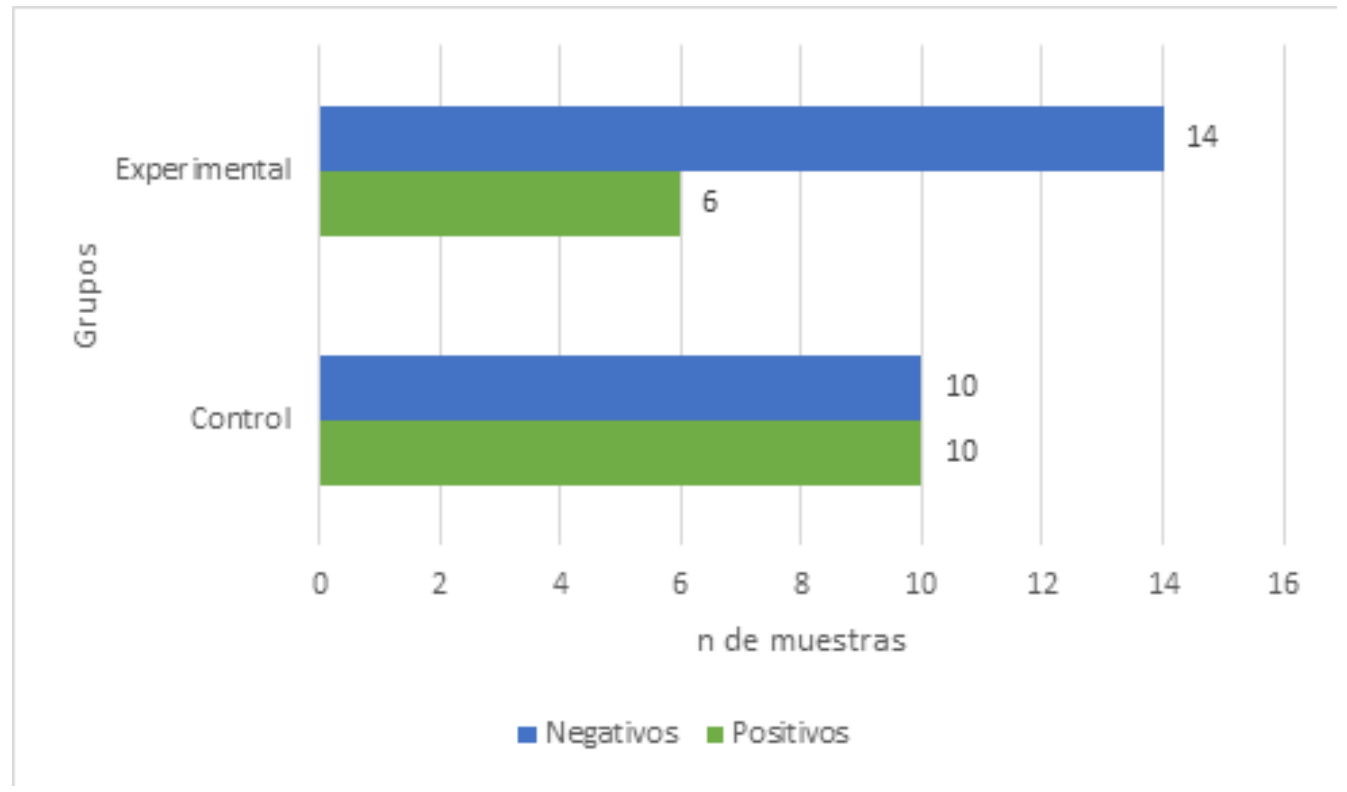

Por otra parte, el cultivo en medio selectivo para bacilos Gram negativos, agar Mac Conkey, no mostró crecimiento a las 48 hrs. En las muestras cultivadas a partir del grupo control. Respecto al LMC 3 tiempos, 2 (10\%) muestras fueron positivas y el microorganismo identificado fue Klebsiella sp.

Si se toma en cuenta el total de los participantes, se identificó Klebsiella sp. en 2 (95\%) muestras.

\section{DISCUSIÓN}

El lavado de manos es una técnica para disminuir los microorganismos patógenos y se utiliza con regularidad antes y después de la atención al paciente.

De acuerdo la OMS, la transmisión de microorganismos patógenos a partir del contacto con los pacientes e insumos tiene varias 
condicionantes, sin embargo, se ha demostrado microorganismos aislados frecuentemente de piel intacta fueron S. aureus, Proteus mirabilis, Klebsiella spp. y Acinetobacter spp. variando entre 100 y 106 UFC/cm2 a partir de pacientes. De forma coincidente, en nuestro estudio se encontró Klebsiella spp. pero no se halló las demás especies mencionadas. Por otra parte los microorganismos permanecen viables en los estratos de la piel normal, donde se encuentran 106 estratos que se desprenden diariamente. La técnica de muestreo que se utilizó en el presente estudio, que fue a través de un barrido con hisopo en la piel de la mano y demuestra la presencia de microrganismos en casi todos los participantes tras el lavado de manos, lo cual evidenciaría la viabilidad de los microrganismos en los estratos de la piel.

Si la contaminación proviene del medio ambiente u objetos, es más probable que sea debida a Staphylococcus, Enterococcus o Clostridium difficile los cuales son más resistentes al ambiente y la desecación. La contaminación del medio ambiente inanimado ha sido también detectada en la sección de lavado de manos y superficies, siendo muchos de los organismos aislados los Staphylococcus. De acuerdo a lo mencionado, nuestros resultados demuestran un elevado índice de crecimiento de Staphylococcus cuagulasa negativo aún después del lavado de manos (WHO ,2009).

Según Ruiz y Urzainqui (2005 ) en un ensayo clínico realizado sobre la eficacia del lavado de manos con solución alcohólica versus jabón antiséptico, midieron la reducción de recuento bacteriológico, siendo de $83 \%$ en lavado con alcohol y de $58 \%$ con jabón antiséptico. Estos datos indican que el utilizar los antisépticos por varias veces, reduce considerablemente el recuento microbiano en manos. En nuestro estudio encontramos diferencia estadísticamente significativa $(p=0.033)$ tras la aplicación de 2 métodos de lavado siendo similar a la publicación mencionada, puesto que en el grupo control se utilizó jabón antiséptico y el LMC de tres tiempos concluye con la aplicación de alcohol en gel.

Investigaciones realizadas en estudiantes del área de salud demuestran la presencia de microorganismos en manos. De acuerdo a Bustamante, et al. (2018), evaluaron la efectividad del lavado de manos clínico a través de bioluminiscencia en estudiantes de Odontología, y demostraron la presencia de microorganismos en distintas proporciones tras el lavado, lo cual coincide con nuestros resultados.

Por otro lado; García, et al (2016) estudió de identificación de crecimiento bacteriano en la palma de las manos de estudiantes universitarios de ciencias de la salud, sin tomar en cuenta lavado de manos, encontró crecimiento bacteriano en solo $50 \%$ de las muestras, a diferencia de nuestros resultados, cuyas muestras fueron tomadas por hisopado y se demostró crecimiento bacteriano en un $97.5 \%$ de los participantes tras el lavado de manos. Por otra parte, los microorganismos encontrados por García, et al. (2016) fueron Escherichia coli, Proteus, Shigella, Streptococcus, Pseudomonas, Staphylococcus, Klebsiella y Clostridium. Nuestra investigación estuvo dirigida a la búsqueda de Staphylococcus y bacilos Gram negativos y de manera similar al estudio mencionado se encontró Staphylococcus coagulasa negativo y Klebsiella spp.

La investigación realizada por Wistrand, Soderquist, Falk, Nilsson (2018) aplicó el lavado de manos quirúrgico en un grupo de enfermeras $(n=12)$, el cual mostró un crecimiento en el $83 \%$ de los participantes. El procedimiento de lavado de manos quirúrgico es de mayor rigurosidad en relación al lavado de manos clínico, y a pesar de esto, hubo un alto porcentaje de crecimiento. El crecimiento bacteriano después del lavado de manos quirúrgico, se observó en el $83 \%$ de las enfermeras y el $46 \%$ de los trabajadores. Las especies aisladas en las enfermeras fueron S. wameri, P. acnés, Bacillus $\mathrm{sp}, \mathrm{S}$. capitis, Micrococcus sp. S. haemolyticus, alpha haemolytic Streptococci. En el grupo de los trabajadores fueron: S. wameri, P. acnés, Bacillus sp, S. capitis, S. haemolyticus, S. epidermidis, Brevibacteriaceae, S. lugdunensis, Enterobacteriaceae. En nuestros resultados se identificó crecimiento de Staphylococcus coagulasa negativo en el $40 \%$ de los participantes y $5 \%$ de BGN (Klebsiella $\mathrm{sp}$ ) en el total de los participantes después de ambos métodos de lavado de manos.

Otro estudio de la eficacia de la higiene de manos con un preparado de base alcohólica vs lavado de manos con agua y jabón, tomo muestras de 103 trabajadores sanitarios. Respecto al lavado de manos con jabón, posterior al lavado se encontró crecimiento en un $15 \%$ de las muestras y con solución alcohólica en un $2.4 \%$. Se encontraron diferencias significativas al comparar número de 
UFC de ambas técnicas $p=0.000$. La solución alcohólica resultó ser eficaz tanto cuando se calculó antes y después, como al compararla con la técnica de lavado con agua y jabón. En cambio la técnica de lavado de manos no resultó ser eficaz (Londoño y Murillas, 2011). En nuestros resultados también encontramos que tras el LMC el crecimiento en UFC fue mucho mayor que al aplicar el lavado de manos en 3 tiempos, el cual finaliza con la aplicación de alcohol en gel; entre ambas técnicas tuvimos una diferencia significativa $p=0.033$ lo que indica que la aplicación del alcohol aumentaría la eficacia del lavado de manos.

Respecto a los microrganismos, Londoño y Murillas (2011) indentificaron Staphylococcus coagulasa negativo en el $25.9 \%$ de 332 muestras y Gram negativos en $2.1 \%$. En nuestro estudio, encontramos Staphylococcus coagulasa negativo en $40 \%$ de muestras y bacilos Gram negativos en el $5 \%$ del total. Un dato importante de compararse es el aumento de BGN tras la aplicación de alcohol en gel, en el estudio mencionado, antes de la aplicación de la solución alcohólica no se encontró Bacilos Gram negativos mientras después de su aplicación se encontraron en 1.2. En nuestro estudio no se encontró BGN posterior al LMC, pero se encontró en 2 muestras, posterior al lavado de manos en 3 tiempos.

\section{CONCLUSIÓN}

Se concluye que a pesar de la aplicación de las dos técnicas de lavado de manos se evidenció crecimiento bacteriano. Respecto a los microorganismos encontrados, se aisló Staphylococcus cuagulasa negativo en un 40 $\%$ de las muestras del total de participantes. De acuerdo a la técnica empleada estos microorganismos fueron más frecuentes tras el lavado de manos clínico de 11 pasos. Asimismo, en cuanto a la búsqueda de bacilos Gram negativos, se encontró Klebsiella spp. en un 5\% del total y únicamente tras el lavado de manos en tres tiempos. Los recuentos bacterianos tuvieron diferencia estadísticamente significativa de $p=0.033$ comparando ambas técnicas de lavado.
Declaración de financiamiento y de conflictos de interés

El estudio fue financiado por los autores, quienes declaran no tener algún tipo de conflicto de interés en la investigación realizada

\section{Correspondencia:}

Raquel Orellana Guevara

Correo electrónico:

raquel.orellana@uab.edu.bo

Celia Colque Flores

Correo electrónico:

celia.colque@uab.edu.bo

\section{REFERENCIAS BIBLIOGRÁFICAS}

Organización Mundial de la Salud. (2014) Directrices de la OMS sobre higiene de manos en la atención sanitaria, Alianza mundial para la seguridad del paciente 2014 Recuperado de https://www.who. int/patientsafety/information_centre/Spanish_ HH_Guidelines.pdf

Allegranzi, B., Kilpatrick, C., Pittet, D. (2011). Higiene de manos. Conceptos básicos de control de infecciones de IFIC. Recuperado de https://www. theific.org/wp-content/uploads/2014/08/Spanish ch10_PRESS.pdf

García, E., García, F., De Dios, I., Uzagahuac, E., López, E., Morales, R., Farías, G., Morales, M., Arévalo, J. (2016). Identificación de crecimiento bacteriano en las manos de estudiantes universitarios de ciencias de la salud. Revista de Sanidad Militar México. 70(5), 453-463. Recuperado de https://www.medigraphic.com/ pdfs/sanmil/sm-2016/sm165e.pdf.

Córdova, R., Cavero, P., Huaranga, J., Pachas, C. (2011). Portadores asintomáticos de Staphylococcus aureus en trabajadores del Hospital Regional de Ica, Perú 2011. Revista Médica. Panacea, 1(3), 59-66. Recuperado de https://revistas.unica.edu.pe/index.php/panacea/ article/view/110

Marples, R., Torres, A., (2012). A laboratory model for the investigation of contact transfer of micro-organisms. Epidemiology and Infection, 82(2), 237-48. Recuperado de https://dx.doi. org/10.1017\%2Fs0022172400025651

Organización Mundial Organización (2009), Cinco Momentos del lavado de manos, Recuperado 
de https://www.who.int/gpsc/information_centre/ gpsc_5_momentos_poster_es.pdf

Oliveira, P., Marques, A., Prado, M. (2017). Infecciones relacionadas con la asistencia a la salud en unidades de terapia intensiva neonatal: una revisión integradora. Revista Enfermería Global, 16(45), 508 - 536. Recuperado de http:// scielo.isciii.es/scielo.php?script=sci_arttext\&pid =S1695-61412017000100508

Corrales, L., Ángel, V., Caicedo, D. (2008). Identificación de Salmonella y Escherichia coli en manos y guantes de manipuladores en planta de sacrificio y faenado de un municipio de Cundinamarca. NOVA - Publicación Científica En Ciencias Biomédicas, 6(9), 101-212. Recuperado de http://hemeroteca.unad.edu.co/index.php/ nova/article/view/392

Bustamante, F., Nuñez, J., Arellano, M., Crot, W., Navarro, P., Fuentes, R. (2018). Bioluminiscencia: herramienta de medicin y análisis en lavado de manos clínico aplicado a la odontología. Int. J. Odontostomat., 12(2), 160-168. Recuperado de https://scielo.conicyt.cl/pdf/ijodontos/ v12n2/0718-381X-ijodontos-12-02-00160.pdf
WHO. (2009) WHO Guidelines on Hand Hygiene in Health Care. World Health Organization. Recuperado de https://apps.who.int/iris/bitstream/ handle/10665/44102/9789241597906_eng.pdf;js essionid=9E51864164B21B327267472857AE45 $\mathrm{CB}$ ? sequence $=1$

Ruiz, R., Urzainqui, O. (2005). Eficacia del lavado de manos con olución De Base Alcohólica Versus El Lavado De Manos Estándar Con Jabón Antiséptico: Ensayo Clínico Controlado Y Aleatorizado. Enfermería Global, 4(1), 15. Recuperado de https://doi.org/10.6018/ eglobal.4.1.532

Wistrand, C., Söderquist, B., Falk, K., Nilsson, U. (2018). Exploring bacterial growth and recolonization after preoperative hand disinfection and surgery between operating room nurses and non-health care workers a pilot study. BMC Infectious Diseases, 18(1). Recuperado de https://doi.org/10.1186/s12879-018-3375-3

Londoño, A., Murillas, M. (2011). Eficacia de la higiene de manos con un preparado de base alcohólica vs lavado de manos con agua y jabón. Acta Medica Colombiana, 36(4). Recuperado de http:// www.scielo.org.co/pdf/amc/v36n4/v36n4a04.pdf

Recibido: 4 de julio Aceptado: 30 de setiembre 